\title{
O OLHAR DOS FORMADORES ACERCA DO TRABALHO REALIZADO NAS INSTITUIÇÕES DE EDUCAÇÃO INFANTIL
}

\author{
Juliana Gonçalves Diniz Fernandes ${ }^{1}$
}

\section{INTRODUÇÃO}

Historicamente destinada aos filhos da mulher trabalhadora, a idéia de Creche como um direito da criança e espaço educativo - bandeira de vários movimentos sociais e reflexo de produções acadêmicas, nas décadas de 60 e 70 - toma corpo a partir da década de 80 com a promulgação da Constituição Federal e, principalmente, com a Lei de Diretrizes e Bases (LDB), sancionada em 1996. Esta Lei passa a denominar o atendimento da criança de zero a três anos em creches e de quatro a seis anos em pré-escolas como Educação Infantil, etapa inicial do Ensino Básico.

A institucionalização desta abordagem da creche dentro da legislação educacional, tornando obrigatório o seu oferecimento pelas instâncias municipais, tem permitido a um grande número de crianças pequenas o acesso a este espaço coletivo de socialização e desenvolvimento.

Conforme Barreto (1998, p. 26), de acordo com levantamentos do IBGE-PNAD de 1995, apenas 7,6\% das crianças brasileiras freqüentavam creche. Porém, conforme dados preliminares apresentados pelo MEC/INEP/SEEC, referentes ao Censo Escolar de 2001, há um significativo crescimento no número de crianças matriculadas em creches no Brasil - na ordem de $186 \%$ - no período de 1998 e $2001 .^{2}$

Tais números, por si só, poderiam representar motivo de júbilo, não fosse a insuficiência e a inconsistência dos desdobramentos daquilo que a legislação propugna, uma vez que o acesso quantitativo não tem se acompanhado de uma real qualificação destes serviços destinados ao desenvolvimento e à socialização da criança pequena, como complemento à ação da família e da comunidade.

Ainda de acordo com Barreto,

\footnotetext{
${ }^{1}$ julianagdf@yahoo.com.br Unesp - Presidente Prudente

2 Anteriormente a este período a maioria das creches ainda estava alocada na Secretaria da Assistência Social,do governo federal, não aparecendo no Censos Escolares.
} 
"A qualidade do atendimento em instituições de educação infantil no Brasil, devido à forma como se expandiu, sem os investimentos técnicos e financeiros necessários, apresenta, ainda, padrões bastante aquém dos desejados, especialmente na creche, que, historicamente, se caracterizou como um atendimento de guarda para crianças de famílias de renda mais baixa, mas também nas pré escolas destinadas a essa faixa da população”( p. 27)

Em 1997, a Secretaria de Educação Fundamental do Ministério da Educação publicava um material organizado pelas pesquisadoras Maria Malta Campos e Fúlvia Rosenberg sistematizando Critérios para um atendimento em creches que respeite os direitos fundamentais das crianças (MEC/SEF/DPEF/COEDI, 1997), embutindo aí uma discussão ainda muito presente nos tempos atuais, qual seja o da qualidade dos serviços oferecidos às crianças pequenas em ambientes coletivos.

Estes critérios e os debates acadêmicos sobre a qualidade na Educação Infantil têm enfatizado a questão da formação de profissionais que atuam neste nível da educação, uma vez que a legislação parece valorizar esta formação especialmente no que diz respeito à concessão de certificados correspondentes a um grau de escolaridade superior.

De acordo com a LDB, em seu artigo 62,

“A formação de docentes para atuar na educação básica far-se-á em nível superior, em curso de licenciatura, de graduação plena, em universidades e institutos superiores, admitidas como formação mínima, para o exercício do magistério da educação infantil e nas quatro primeiras séries do ensino fundamental, a oferecida em nível médio, na modalidade Normal”.

E, em seu artigo 87, parágrafo 4o.

“Até o final da Década da Educação somente serão admitidos professores habilitados em nível superior ou formados por treinamento em serviço".

Entretanto, ações institucionais que, efetivamente, avancem em direção à qualidade e à valorização deste profissional tem sido insuficientes: além de iniciativas consistentes e 
academicamente valiosas serem abortadas $^{3}$, a legislação tem se colocado como forma de pressão para que os profissionais que ainda não possuem a titulação exigida, a obtenham por meio da freqüência a cursos, cujas condições didático-pedagógicas nem sempre oferecem uma formação de qualidade e de valorização profissional.

Com efeito, em busca de se adequarem à legislação, os profissionais da educação vêm se submetendo à degradante situação de financiar a obtenção de seus diplomas nos chamados “cursos vagos", - porém autorizados por órgãos do próprio governo - de modo a garantirem sua inclusão no mercado de trabalho.

\section{Então, qual formação?}

Antes da promulgação da LDB em 1996, grupos de especialistas e pesquisadores ligados, à época, ao MEC, organizaram seminários a respeito das várias questões em torno da Educação Infantil, produzindo documentos e publicações extremamente valiosas.

Dentre estas publicações destacamos Política Nacional de Educação Infantil e Por uma Política de Formação do Profissional de Educação Infantil, ambas divulgadas em 1994.

Neste último, encontramos no artigo de Maria Malta Campos "Educar e Cuidar: questões sobre o perfil do Profissional de Educação Infantil”, apontamentos bastante interessantes.

O núcleo de seu artigo se coloca na questão dos objetivos da educação infantil.

"Quando pensamos no perfil do profissional de educação infantil que queremos, é preciso antes caracterizar os objetivos que desejamos alcançar com as crianças” (p. 32).

Se em seu passado filantrópico as creches admitiam pessoas para uma atuação que não extrapolava os cuidados necessários à sobrevivência das crianças, ao assumir-se o caráter educativo destas instituições - equivocadamente, através do viés da escolarização - o perfil de seus profissionais passou a identificar-se com aquele do professor, muito embora, na realidade o que ainda se encontra na grande maioria das creches, sejam elas filantrópicas ou públicas, é a presença de educadores leigos.

\footnotetext{
${ }^{3}$ A interrupção de projetos gestados a partir de seminários e debates realizados por especialistas, que também produziram para a Coordenação de Educação Infantil (COEDI) do MEC, em 1994, a série de textos básicos para uma política nacional de educação infantil - os "rostinhos de crianças"- é exemplar desta nossa afirmação.
} 
Ainda conforme Maria Malta Campos (1999)

"Quando consideramos os profissionais da educação, confirma-se por toda a parte a regra que estabelece que quanto menor a criança a se educar, menor o salário e o prestigio profissional de seu educador e menos exigente o padrão de sua formação prévia” (p. 131).

Contudo, os estudos sobre o desenvolvimento infantil, sobre a evolução histórica das concepções acerca da infância e sobre a educação de crianças pequenas têm apontado para um profissional que, em contextos de creche, exerça funções de cuidar e educar, postas de modo indissociável e integrado.

Também no documento Por uma Política de Formação do Profissional de Educação Infantil, Sonia Kramer aponta:

"Se a educação infantil fundamenta-se no binômio educar/cuidar, a formação de seus profissionais deve também pautar-se nele. A conjugação destas atividades, bem como o preparo para exercê-las,precisa necessariamente despir-se de uma visão hierarquizada das atividades de educar e cuidar, uma vez que ambas partilham de igual importância no cotidiano da educação infantil.” ( p. 78)

Embora as funções de cuidar/educar estejam colocadas em textos teóricos e acadêmicos, bem como na legislação em vigor, deixando claro que seu exercício requer uma formação de grande especificidade e complexidade, não se encontra uma clareza conceitual acerca destas especificidades e complexidades, sequer a delimitação do campo de trabalho das educadoras de creche e seu perfil profissional.

A partir da promulgação da Lei de Diretrizes e Bases, em 1996, foram elaborados documentos norteadores para os diversos níveis de escolaridade, entre eles o Referencial Curricular para Educação Infantil e os Referenciais para Formação de Professores.

O Referencial Curricular Nacional para a Educação Infantil, fundamentado em experiências educacionais realizadas no país e no exterior, tem sido alvo de diversas críticas quanto ao seu conteúdo excessivamente teórico e distante das condições reais da sociedade brasileira. 
Thereza Montenegro (2001) se ocupa em pinçar neste documento diversas passagens nas quais estão expressas concepções de cuidado - dentro do binômio cuidar/educar - sem que este mesmo documento, oficial e orientador, forneça pistas sobre como poderiam ser desenvolvidas,em seu processo de formação, habilidades para que os educadores de creche possam ocupar-se desta função de cuidar.

Do mesmo modo, os Referenciais para Formação de Professores, material divulgado pela Secretaria de Educação Fundamental do Ministério da Educação apontam para orientações extremamente genéricas, oferecendo oportunidades para que inúmeros modelos de formação - e de variável qualidade e consistência - sejam implantados no país.

Se, como apontamos, a atual legislação tem o mérito de procurar assegurar uma escolarização em nível superior para o profissional da educação infantil, há também que se expor sua face perversa: por um lado, condiciona a inclusão ou permanência no mercado de trabalho à posse de um diploma de nível superior e, por outro, favorece a criação de cursos (principalmente na iniciativa privada) de curta duração que oferecem uma formação aligeirada e técnica como é o caso do Curso Normal Superior, dos cursos sequienciais e dos cursos à distância, seja para a formação inicial ou continuada.

Todo o quadro exposto, no qual procuramos registrar os aspectos polêmicos das discussões que vêm ocorrendo sobre a formação de profissionais para a educação infantil, nos conduz à tentativa de desvendamento da seguinte questão:

- Muito além do discurso oficial, sob quais concepções os cursos Normal e de Pedagogia têm organizado seus currículos e seus conteúdos de modo que formem estes profissionais?

\section{OBJETIVOS:}

Considerando que os professores de curso de Normal e Pedagogia são os formadores dos educadores de creche, investigamos como estes formadores compreendem o trabalho do educador de creche.

\section{METODOLOGIA:}

\subsection{As entrevistas e as formadoras:}


Utilizamos a entrevista temática, assegurando como eixo da investigação, a busca de referências sobre "como professoras de cursos de Pedagogia e Normal compreendem o trabalho das educadoras de creche, que supostamente elas então formando".

Nossa escolha pela entrevista temática, deu-se no sentido de obtermos falas com conteúdos menos determinados e controlados por conhecimentos teóricos: por se tratar de profissionais que, por força de ofício, devem ter domínio teórico, racional, sobre questões que desejamos investigar, entendemos que entrevistas apenas orientadas por um roteiro pertinente ao objeto de investigação, com um dinamismo que permitia o aprofundamento das respostas, poderia favorecer o surgimento de falas espontâneas, menos "mascaradas" por conhecimento livresco, mais ricas para uma análise posterior.

Para a realização das entrevistas, elaboramos um roteiro que utilizamos como norteador da nossa interlocução com as entrevistadas.

Para este roteiro, estabelecemos alguns temas que nos permitissem circundar a nossa questão principal, complementando-a em seus significados. Entre estes temas, os seguintes:

* clientela que busca os cursos de Pedagogia e Normal;

* contribuição dos cursos de Normal e Pedagogia para a formação das educadoras de creche;

* disciplinas e conteúdos que podem contribuir mais diretamente para a formação das educadoras de creche;

* conhecimentos que as formadoras têm acerca da instituição creche e de educadoras de creche;

* idealização quanto à instituição creche e educadoras que aí atuam;

* aspectos profissionais e pessoais associados às atividades que educadoras de creche exercem;

Foram realizadas entrevistas com seis professoras que ministram aulas em cursos de Normal e Pedagogia oferecidos pela iniciativa privada, na cidade de Assis-SP. 
Estes cursos funcionam em período noturno e, por serem os únicos da região, são bastante concorridos. Caracterizam-se pela clientela basicamente feminina e de pessoas que já se encontram exercendo atividades em docência, principalmente no ensino básico - incluindo a educação infantil - e fundamental.

A maioria destas formadoras possui experiência no ensino, anterior à função que exerce atualmente, sendo que várias delas têm história profissional ligada ao ensino fundamental e à rede pública.

\section{RESULTADOS:}

A partir das transcrições, foi possível agrupar as falas das formadoras em torno de alguns "núcleos de significação do discurso" ${ }^{4}$ considerando, tanto a freqüência quanto a ênfase com que alguns temas apareceram.

Assim, pudemos selecionar, para a análise, os temas abaixo que, contudo, em diversos momentos se entrecruzam, conforme apresentaremos na análise das entrevistas:

- Contribuições dos cursos Normal e de Pedagogia para a formação das educadoras de creche.

- Concepção e idealização de creche;

- Concepção e idealização de educador de creche;

- Compreensão sobre as relações entre creche e família.

No seu conjunto, as entrevistas revelam que a maioria das formadoras possui informações dispersas acerca de educação infantil e, mesmo neste caso, restritas à legislação atual e aos documentos oficiais, que, como já apontamos anteriormente carecem de maior clareza e objetivação.

Assim, em diversas circunstâncias durante as entrevistas, foi possível verificar que, frente a alguma pergunta que parecesse exigir uma informação ou um conhecimento baseado em experiência profissional ou em bibliografia específica algumas formadoras reagiam com

\footnotetext{
${ }^{4}$ Conforme denominação de AGUIAR,W.J. (2001) p. 129-140
} 
prolixidade ou digressões, conforme pode ser constatado nas transcrições apresentadas em Anexo.

Foi possível também se observar que as entrevistadas não possuem uma visão de conjunto acerca do curso em que atuam, seja o Normal ou a Pedagogia, ou sequer sobre uma proposta pedagógica que defina os objetivos dos mesmos. Nas falas, predomina o personalismo, muitas vezes reafirmado no sentido de que "falam por si próprias", ignorando o trabalho de suas colegas.

Verificamos, ainda, a partir das falas - e corroborando pesquisas na área - que as grades curriculares de ambos os cursos não oferecem disciplinas ou conteúdos especificamente relacionados à infância e à educação infantil, nem à docência neste nível.

\section{DISCUSSÃO E CONCLUSÕES:}

O campo da formação de profissionais para a educação é extremamente vasto e complexo e vem merecendo atenção privilegiada dos estudiosos e pesquisadores, tanto na própria educação como em áreas afins.

A partir da promulgação da Lei de Diretrizes e Bases, em 1996 e da legislação daí decorrente, estes trabalhos se intensificaram na direção dos aspectos políticos das questões educacionais postas na Lei.

Com referência à educação infantil, a formação de seus profissionais tem sido alvo de inúmeros trabalhos, embora a discussão desta temática não seja novidade no âmbito acadêmico, estando em estudos desde a década de 70 no Brasil.

Entretanto, há um movimento muito peculiar que vem ocorrendo como uma das implicações da legislação atual. Trata-se da exigência da formação de profissionais, em nível superior, para atuarem na educação infantil, acarretando uma busca desenfreada por cursos superiores, cuja instalação também foi favorecida pela legislação.

Contudo, a literatura especializada vem demonstrando que os documentos oficiais, norteadores de todas estas reformas, são bastante obscuros quanto ao perfil de educador de crianças pequenas e às especificidades de sua formação, principalmente no que tange às funções de cuidar/educar apropriadas para as crianças de zero a três anos que freqüentam as creches. 
$\mathrm{O}$ fato de que um número cada vez maior de crianças vem tendo acesso à educação infantil, tem gerado uma preocupação crescente com relação ao que, efetivamente, este espaço coletivo representa de contribuição para o desenvolvimento integral destas crianças. E, neste cenário, o adulto educador, desempenha um papel fundamental.

No presente estudo, procuramos conhecer, através de entrevistas temáticas, as concepções que seis professoras de cursos Normal e de Pedagogia de uma cidade do interior do estado de São Paulo têm a respeito do trabalho que, por suposição, suas alunas deveriam desenvolver em creches.

Em seu conjunto, estas formadoras parecem se ater ao discurso oficial, traduzindo como compreensão sua, aquilo que está posto nos principais documentos e legislações pertinentes à educação infantil.

Desta forma, compreendem de modo bastante naturalizado e simplista, o fato de suas alunos estarem buscando sua titulação nos cursos Normal e Pedagogia, porque assim requer a lei.

Embora reconheçam como novidade posta na lei, o fato da creche estar colocada no capítulo da educação, parecem não ter clareza quanto às funções concretas deste espaço institucional, variando desde uma visão assistencialista/filantrópica até uma visão compensatória, de estimulação e preparo para a escola fundamental, visão esta de pré-escola muito comum nas décadas de 70-80 e baseada nas teorias da privação cultural.

Mesmo considerando que a maioria das entrevistadas faz referência a alguma experiência profissional no ensino fundamental e mesmo infantil, certamente, por conta de visão distanciada da nova realidade, não revela familiaridade com o tema creche, principalmente no que diz respeito às práticas a serem exercidas neste ambiente. Ao desconhecerem estes aspectos, observase o descolamento do que imaginam ser tais funções e os conteúdos que ministram em suas disciplinas.

As falas das formadoras entrevistadas parecem revelar que, ao exercerem sua função pedagógica, compõem seus conteúdos programáticos tanto com referências teóricas sedimentadas (como é o caso de Piaget, Vigostky, Emilia Ferrero) com referências documentais (como é o caso das Diretrizes) e com opiniões e conceitos próprios, fundamentados em idéias que já foram, 
teoricamente, superadas e mesmo criticadas nos documentos oficiais, como é o caso da visão inatista de desenvolvimento humano.

Ao procurarem identificar as funções da instituição creche, as formadoras entrevistadas, de modo geral, acreditam ser este o espaço no qual devem ser oferecidas as condições que as famílias pobres não podem proporcionar a seus filhos, bem como o preparo para o ensino fundamental, em um ambiente seguro, estimulante, higienizador, conduzido por mulheres maduras, experientes, carinhosas e sensíveis, oferecendo-se como exemplos e modelos para estas crianças.

Observa-se, desta forma, a reiteração, não apenas do discurso oficial, como já apontamos, mas da reafirmação das concepções sobre a creche como substituta do lar, em suas diversas dimensões, ainda presentes no imaginário social.

Do mesmo modo, verificamos nas diversas falas a reiteração de estigmas relacionados às famílias pobres e suas relações com a escola, tão presentes em contextos educacionais do ensino fundamental.

De fato, conforme aponta Silvia Helena Vieira Cruz (1996) “... é preciso rever a visão preconceituosa que essas profissionais muitas vezes têm dos valores, hábitos e costumes das famílias usuárias das creches e pré-escolas públicas a fim de, realmente, poder torná-las como parceiras e utilizar o conhecimento acerca desses temas na elaboração de propostas que tenham significado para as crianças e ampliem seus conhecimentos" (Vieira Cruz, 85-86).

Mesmo, ao que parece, ignorando as funções da creche e de seus educadores - ou baseadas nas concepções que apontamos anteriormente sobre a creche - as entrevistadas reconhecem não ser o atual curso de Pedagogia o locus privilegiado para a formação destes profissionais e apontam o curso Normal como o mais adequado, além da importância dos cursos de especialização e outros que promovam uma formação continuada.

Não parece ser demasiada ousadia supor que, diante do desconhecimento da realidade concreta da instituição creche e dos profissionais que aí atuam, a formação que as entrevistadas vem oferecendo, em suas disciplinas específicas, para as educadoras de creche que cursam o Normal e a Pedagogia, advém, basicamente de quatro vertentes:

○ o conhecimento acadêmico livresco; 
○ o conhecimento a partir dos textos e documentos que subsidiam a atual legislação;

○ o conhecimento obtido em suas próprias formações;

○ o senso comum.

O peso de cada uma destas vertentes, não é possível ser estabelecido.

Porém, nas discussões e debates acadêmicos sobre a formação de educadores de creche além daqueles que vêm tratando das questões macro estruturais - merecem ser focalizados os saberes que são transmitidos, formal ou informalmente para a clientela que hoje busca, nos cursos destinados à formação inicial, um certificado que lhes permita exercer suas funções em creches.

Talvez - e do mesmo modo que nas salas da educação infantil - novas investigações devam ser conduzidas no sentido de serem desvendadas e interpretadas as trocas e interlocuções - afetivas e cognitivas - que, efetivamente estão presentes no dia-a-dia da sala de aula e envolvidas na formação dos profissionais da educação.

\section{BIBLIOGRAFIA:}

BARRETO, A.M.R.F.'Situação atual da Educação Infantil no Brasil' In: BRASIL, Ministério da Educação. Secretaria de Educação Fundamental. Coordenação Geral de Educação Infantil, Subsídios para Credenciamento e Funcionamento de Instituições de Educação Infantil, 1998, Vol II, p.23-33

BRASIL, Ministério da Educação e do Desporto, SEF/COEDI Critérios para um atendimento em creches que respeite os direitos fundamentais das crianças Brasília, MEC/SEF/ DPE/COEDI, 1997

BRASIL, Ministério da Educação e do Desporto. Secretaria de Educação Fundamental. Departamento de Política Educacional. Coordenação Geral de Educação Infantil, Por uma política de formação de profissional de educação infantil. Brasília, MEC/SEF/ DPE/COEDI, 1994.

BRASIL, Ministério da Educação e do Desporto. Secretaria de Educação Fundamental. Departamento de Política Educacional. Coordenação Geral de Educação Infantil. 
Referencial Curricular Nacional para a Educação Infantil. Brasília, MEC/SEF/DPE/COEDI, 1998

BRASIL, Ministério da Educação e do Desporto. Secretaria de Educação Fundamental. Departamento de Política Educacional. Coordenação Geral de Educação Infantil. Política Nacional de Educação Infantil Brasília, MEC/SEF/DPE/COEDI, 1994

BRASIL, Ministério da Educação. Secretaria de Educação Fundamental. Coordenação Geral de Educação Infantil, Referenciais para a Formação de Professores Brasília, MEC/SEF/ DPE/COEDI, 1999

CAMPOS, M. M. "A Formação de professores para crianças de 0 a 10 anos: modelos em debate”. Educação \& Sociedade (São Paulo), p.126-142, ano XX, n. 68, dez. 1999

CAMPOS, M.M. "Educação Infantil: o debate e a pesquisa" In Cadernos de Pesquisa, número 101, pp. 113-117, julho de 1997.

CAMPOS, M.M.A.; GROSBAUM, M.W.; PAHIM, R.; ROSEMBERG, F. "Profissionais de Creche” In Cadernos Cedes, 9, Educação Pré-escolar: desafios e alternativas. São Paulo: Cortez Editora, 1987.

CAMPOS, M.M. Pré Escola: entre a educação e o assistencialismo In Cadernos de Pesquisa, São Paulo, n. 53,p.21-24, 1985.

CRUZ, S.H.V. "Reflexóes acerca da formação do educador infantil”. Cadernos de Pesquisa, no. 97, p. 79-88, maio de 1996

FARIA, A. L. G.; PALHARES, M.S. (orgs.) Educação Infantil pós-LDB: rumos e desafios. São Paulo: Editora Autores Associados, 1999.

FARIA, S.C. "História e Políticas de Educação Infantil” in: KRAMER,S. et al. (org.) Educação Infantil em Curso. Rio de Janeiro: Ravil, 1997.

FAZOLO, E.; CARVALHO, M.C.C. P de; KRAMER, S. et al. (org.) Educação Infantil em Curso. Rio de Janeiro: Ravil, 1997. 
GUIMARÃES, D.; NUNES, M.F.R.; LEITE,M.I. “História, Cultura e Expressão: Fundamentos na Formação do Professor". In KRAMER, S; LEITE, M.I; NUNES, M.F.; GUIMARÃES, D. (orgs.) Infância e Educação Infantil. São Paulo: Papirus Editora, 1999.

KUHLMANN JUNIOR, M. Infância e Educação Infantil: uma abordagem histórica. Porto Alegre: Mediação, 1998.

MACHADO. M. L. Formação Profissional para educação infantil: subsídios para idealização e implementação de projetos. São Paulo, 1998, tese de doutorado.

MERISSE,A "Origens das Instituições de Atendimento à criança pequena: o Caso das Creches" In: MERISSE,A. (et al.) Lugares da Infância: reflexões sobre a história da criança na fábrica, creche e orfanato SP: Arte \& Ciência, 1997.

RIVERO, A .S. Da Educação Pré Escolar á Educação Infantil: um estudo das concepções presentes na formação dos professores no Curso de Pedagogia. (texto apresentado na Reunião da Anped, no GT Ed. Infantil, 2001)

SILVA, Ana Paula Soares; ROSSETI-FERREIRA, M. Clotilde (FFCLRP/USP) Desafios atuais da educação infantil e da qualificação de seus profissionais: onde o discurso e a prática se encontram? Texto apresentado na $23^{\mathrm{a}}$ Reunião da ANPED em 2000. 


\section{O olhar dos formadores acerca do trabalho realizado nas Instituições de Educação Infantil}

Juliana Gonçalves Diniz Fernandes, Unesp - Presidente Prudente

Apesar da atual legislação alocar a Creche como uma etapa inicial do sistema educacional brasileiro, esta instituição ainda é representada socialmente como um espaço voltado ao atendimento das necessidades da mãe trabalhadora, no qual as atividades desenvolvidas estão associados à maternagem e à puericultura. Considerando que estes profissionais devem buscar sua formação junto aos cursos de magistério e pedagogia, estudamos, através de entrevistas abertas feitas com seis professoras de cursos de magistério e pedagogia, qual a compreensão que estas formadoras têm a respeito do trabalho do educador de creche. A análise das falas das formadoras foi feita a parir de categorias: concepção e idealização de creche; concepção e idealização de educador de creche; contribuições dos cursos de magistério e pedagogia para a formação dos educadores de creche; relações creche e famílias. 